\title{
Congenital Dermatofibrosarcoma Protuberans: A Case Report and Literature Review
}

\author{
Hyun Ho Han, Soo Yeon Lim, Young Min Park ${ }^{1}$, Jong Won Rhie \\ Departments of Plastic and Reconstructive Surgery and ${ }^{1}$ Dermatology, College of Medicine, The Catholic University of Korea, Seoul, Korea
}

\begin{abstract}
Congenital dermatofibrosarcoma protuberans (DFSP) is an extremely rare skin tumor that is commonly misdiagnosed, or is often diagnosed long after the initial presentation. Although many cases of DFSP are diagnosed in adulthood, there are some differences between adult DFSP and congenital DFSP. We report a case of congenital DFSP that was initially misdiagnosed as a simple vascular lesion. The delay in diagnosis led to the considerable growth of the lesion, such that a huge scar was left after the surgical treatment. The major differences between adult and congenital DFSP are discussed through a literature review. Clinicians should be aware of the characteristics of congenital DFSP, to reduce misdiagnosis and the delay of diagnosis from the initial presentation. (Ann Dermatol 27(5) 597 600, 2015)
\end{abstract}

\section{-Keywords-}

Age of onset, Congenital, Dermatofibrosarcoma, Diagnosis

\section{INTRODUCTION}

Congenital dermatofibrosarcoma protuberans (DFSP) is an extremely rare skin tumor that is commonly misdiagnosed, or is often diagnosed long after the initial presentation.

Received September 2, 2014, Revised January 19, 2015, Accepted for publication February 5, 2015

Corresponding author: Jong Won Rhie, Department of Plastic and Reconstructive Surgery, Seoul St. Mary's Hospital, College of Medicine, The Catholic University of Korea, 222 Banpo-daero, Seocho-gu, Seoul 06591, Korea. Tel: 82-2-2258-6142, Fax: 82-2-594-7230, E-mail: rhie@ catholic.ac.kr

This is an Open Access article distributed under the terms of the Creative Commons Attribution Non-Commercial License (http:// creativecommons.org/licenses/by-nc/4.0) which permits unrestricted non-commercial use, distribution, and reproduction in any medium, provided the original work is properly cited.

\section{CASE REPORT}

DFSP is a rare cutaneous tumor of fibrohistiocytic origin characterized by intermediate malignancy ${ }^{1}$. It is rare in children, and congenital cases are even more scarce ${ }^{2,3}$. Its diagnosis is also very difficult unless a biopsy is done.

An otherwise healthy 6-year-old girl was referred to our plastic and reconstructive unit by the dermatologic unit for the evaluation of an irregularly oval and indurated purplish plaque on the posterior neck. An area of the plaque showed a yellowish color (Fig. 1). It had been present like a bruise since birth and progressively became enlarged over time. This lesion was previously examined with punch biopsy by local dermatologists 2 years ago. It showed papillomatosis and slight hyperpigmentation of the basal layer of the epidermis; however, it did not present as a malignancy. At that time, the patient was treated with antihistamine pills and local steroid injection therapy; however, none of them helped improve her itchiness or intermittent pain.

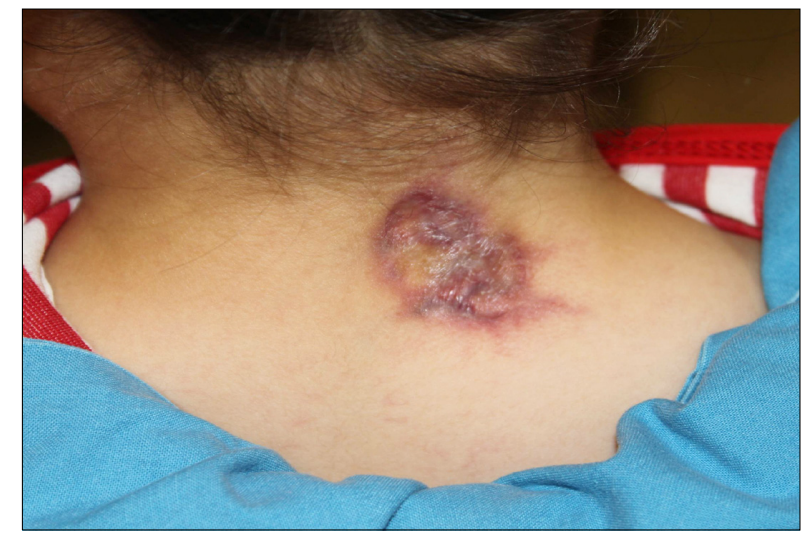

Fig. 1. An about $2.0 \times 2.0 \mathrm{~cm}$ irregular erythematous-violaceous plaque showing an atrophic change with a scar tissue in the central portion on the posterior neck region. An area in the plaque shows a yellowish color. 
The pathologic slide, made 2 years ago by a local dermatologist, was reviewed by our dermatology department. It showed histiocytes, and non-Langerhans cell histiocytosis needed to be ruled out. Typical pathologic findings for DFSP were not observed. For the pathologic confirmation, biopsy was again done by the dermatologic department. A specimen revealed dermal and subcutaneous infiltration of spindle cells within a myxoid stroma forming intersecting fascicles (Fig. 2). The immunohistochemical examination revealed a strong positivity for CD34 and vimentin, whereas S-100, smooth muscle actin, and factor XIIla were negative, which were consistent with DFSP. Furthermore, no cytogenic abnormalities were found.

On physical examination, an about $2.0 \times 2.0 \mathrm{~cm}$ irregular erythematous to violaceous plaque showing a focal atrophic hypopigmented scar tissue in the central portion was examined on the patient's posterior neck region. No evidences for metastasis were found.

Under general anesthesia, a wide excision with a safety margin of $3 \mathrm{~cm}$ was performed. The deep fascia and a portion of the muscle under the central part of the specimen were also included. The resulting defect was reconstructed with a bilobed transpositional fasciocutaneous flap from the interscapular area.

The histopathology confirmed DFSP with clear margins. There was no evidence of recurrence after 4 years (Fig. 3).

\section{DISCUSSION}

DFSP is a rare disease with an incidence of 0.08 per $100,000^{4}$. Especially, congenital DFSP is extremely rare re. $^{2,3}$. The tumor is a slow-growing infiltrative dermal neoplasm with little metastatic potential. However, it shows a rela-

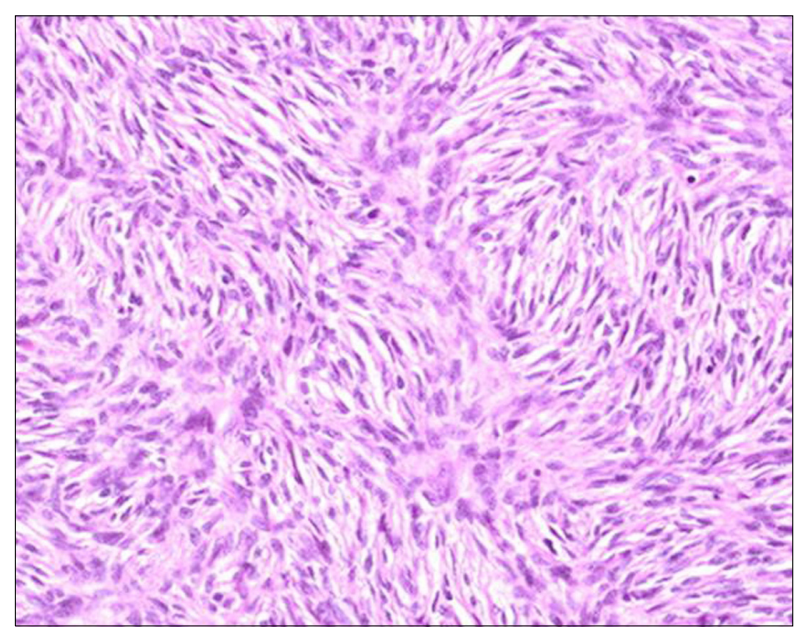

Fig. 2. Typical spindle cells arranged in a storiform pattern infiltrating the dermis $(H \& E, \times 400)$. tively high recurrence rate after surgical resection, and distant metastasis is rarely reported ${ }^{5}$. It is mostly seen during the early to mid-adult life $e^{6}$. Although a variety of diagnostic features have been recognized in the clinic, DFSP is difficult to diagnose when it presents as a simple plaque type without a nodule.

The patient in this case also had a bluish plaque on her posterior neck since birth; however, several local clinics considered the plaque to be a vascular lesion, and therefore no treatment was given. Therefore, the diagnosis as DFSP after a biopsy was delayed for 2 years. As a result of the delay, the DSFP became enlarged and a huge scar was left throughout her posterior neck through her back after the wide excision and transpositional fasciocutaneous flap coverage. It is unfortunate that she did not receive proper diagnosis and treatment at an earlier stage of the disease.

A review of the literature revealed that both congenital and adult DFSP can begin either as a small firm nodule or as a plaque-like lesion ${ }^{7,8}$. These lesions are freely movable in the underlying tissue and are usually fixed to the overlying skin. The color of the DFSP was brown to bluish-red, with a blue or red discoloration in the surrounding tissue. It is easily misdiagnosed as a vascular lesion because a bluish discoloration is often seen in the early stage of plaque-type DFSP ${ }^{8}$. As most congenital DFSPs become known in the early stage of the disease, it is essential for clinicians to be aware of the presentation during this period. The early-stage plaques are present in three different variants as follows: (i) an indurated flap plaque; (ii) a morphea-like, depressed sclerotic plaque; or (iii) an anetoderma-like depressed soft plaque ${ }^{3}$. This case is compatible with the sec-

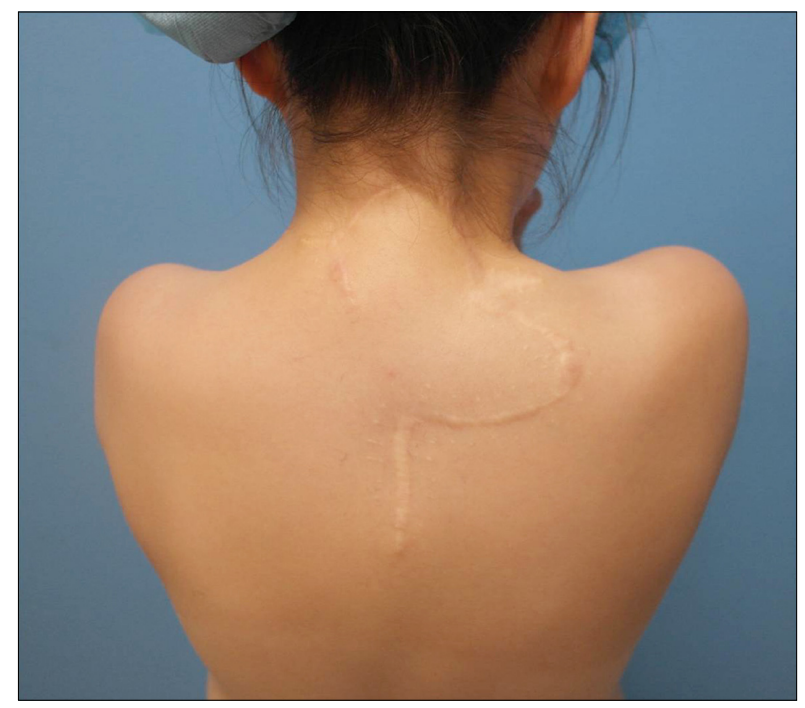

Fig. 3. Photograph at 4 years after surgery. The defect is covered with a bilobed transpositional fasciocutaneous flap. 
Table 1. The differences between adult dermatofibrosarcoma protuberans (DFSP) and congenital DFSP through the literature review

\begin{tabular}{lll}
\hline & \multicolumn{1}{c}{ Adult DFSP } & \multicolumn{1}{c}{ Congenital DFSP } \\
\hline Appearance & Varies from small firm nodule to plaque-like lesion & Mostly nonprotuberans simple plaque type \\
Histopathology & $\begin{array}{c}\text { Tumor cells show typical sievelike entrapment of } \\
\text { fat cells with storifirm or whorled pattern }\end{array}$ & $\begin{array}{c}\text { Similar to the typical type, but the cells are distributed } \\
\text { more loosely }\end{array}$ \\
$\begin{array}{l}\text { Immunohistochemistry } \\
\text { Cytogenic abnormalities } \\
\text { Treatment }\end{array}$ & $\begin{array}{l}\text { Mostly } \mathrm{t}(17 ; 22)(\mathrm{q} 22 ; \mathrm{q} 13) \\
\text { Wide excision, Mohs micrographic surgery, } \\
\text { radiotherapy, chemotherapy (imatinib metylase) }\end{array}$ & $\begin{array}{c}\text { Not found yet } \\
\text { Wide excision, Mohs micrographic surgery, radiotherapy, } \\
\text { chemotherapy (vinblastine, oral methotrexate) }\end{array}$ \\
\hline
\end{tabular}

ond type. Thus, early-stage DFSP such as congenital DFSP tends to be misdiagnosed as a vascular lesion. Likewise, a differential diagnosis with morphea, atrophoderma, atrophic scar and lipoatrophy, keloid, and hypertrophic scar is needed $^{9,10}$. This is why it is crucial for plastic and reconstructive surgeons, dermatologists, pediatricians, and family physicians to know well about the presentation of early-stage congenital DFSP.

On histopathological examination, DFSP shows typical sieve-like entrapment of fat cells infiltrating the subcutaneous tissue ${ }^{6,7,11}$. The typical finding of DFSP consists of a storiform or whorled and moderately cellular pattern, and it is composed of atypical CD34-positive spindle cells. In the congenital type, the findings are mostly similar to the typical type but the cells are distributed more loosely so that the storiform pattern may not be seen, like in our case $^{6,12,13}$. Also, in this case, the first histopathologic finding showed only papillomatosis and slight hyperpigmentation of the basal layer of the epidermis without the storiform pattern, leading to a misdiagnosis. The immunohistochemistry of the spindle cells can be helpful for the differential diagnosis. The immunohistochemistry markers used for DFSP is CD34 for positivity and factor XIIla and S-100 for negativity.

Advancement in diagnostic methods has allowed the identification of cytogenic abnormalities in DFSP. The most frequent abnormality is a supernumerary ring chromosome containing the sequences of chromosome 17 and 22 . Furthermore, although less frequently, a reciprocal translocation, $\mathrm{t}(17 ; 22) \mathrm{q}(22 ; 13)$, has also been described. However, these are mainly applicable to adult DFSP. According to the present report, the cytogenic abnormalities of chromosome 17 and 22 in the congenital type are not yet known ${ }^{3,14}$. It was also consistent with our result.

Thus, it is possible to determine the differences between adult DFSP and congenital DFSP through a review of the available literature. Those differences are summarized in Table $1^{3,6-8,10,11-15}$. Congenital DFSP is rare, and only a few cases have been reported. There is a possibility of delayed diagnosis in adulthood, as the disease is very difficult to diagnose in the early stage of plaque formation, especially in children. Early diagnosis is important to ensure an appropriate wide excision, to reduce the dimensions of the surgical scar, and to avoid the need for extensive surgery requiring reconstruction. To do this, specialized clinicians, such as plastic and reconstructive surgeons, dermatologists, pediatricians, and family physicians, who may have primary contact with the congenital DFSP, need to be aware of the features of the disease.

\section{REFERENCES}

1. Navarro M, Requena C, Febrer I, Marin S, Aliaga A. Dermatofibrosarcoma protuberans with onset in early childhood: a case report. J Eur Acad Dermatol Venereol 2002; 16:154-155.

2. Reddy C, Hayward P, Thompson P, Kan A. Dermatofibrosarcoma protuberans in children. J Plast Reconstr Aesthet Surg 2009;62:819-823.

3. Jafarian F, McCuaig C, Kokta V, Laberge L, Ben Nejma B. Dermatofibrosarcoma protuberans in childhood and adolescence: report of eight patients. Pediatr Dermatol 2008;25: 317-325.

4. Bendix-Hansen K, Myhre-Jensen O, Kaae S. Dermatofibrosarcoma protuberans. A clinico-pathological study of nineteen cases and review of world literature. Scand J Plast Reconstr Surg 1983;17:247-252.

5. Goldblum JR, Folpe AL, Weiss SW. Fibrohistiocytic tumors of intermediate malignancy. In: Goldblum JR, Folpe AL, Weiss SW, editors. Enzinger and Weiss's soft tissue tumors. 6th ed. St. Louis: CV Mosby, 2014:387-420.

6. Taylor HB, Helwig EB. Dermatofibrosarcoma protuberans. A study of 115 cases. Cancer 1962;15:717-725.

7. McPeak CJ, Cruz T, Nicastri AD. Dermatofibrosarcoma protuberans: an analysis of 86 cases-five with metastasis. Ann Surg 1967;166:803-816.

8. Burkhardt BR, Soule EH, Winkelmann RK, Ivins JC. Dermatofibrosarcoma protuberans. Study of fifty-six cases. Am J Surg 1966;111:638-644.

9. Gloster HM Jr. Dermatofibrosarcoma protuberans. J Am Acad Dermatol 1996;35:355-374. 
10. Weinstein JM, Drolet BA, Esterly NB, Rogers M, Bauer BS, Wagner $\mathrm{AM}$, et al. Congenital dermatofibrosarcoma protuberans: variability in presentation. Arch Dermatol 2003; 139:207-211.

11. Pack GT, Tabah EJ. Dermato-fibrosarcoma protuberans. A report of 39 cases. AMA Arch Surg 1951;62:391-411.

12. Cohen PR, Rapin RP, Farhood Al. Dermatofibroma and dermatofibrosarcoma protuberans: differential expression of CD34 and factor XIIla. Am J Dermatopathol 1994;16:573-574.

13. Prieto VG, Reed JA, Shea CR. CD34 immunoreactivity distinguishes between scar tissue and residual tumor in re-excisional specimens of dermatofibrosarcoma protuberans. J Cutan Pathol 1994;21:324-329.

14. Rubin BP, Schuetze SM, Eary JF, Norwood TH, Mirza S, Conrad EU, et al. Molecular targeting of platelet-derived growth factor B by imatinib mesylate in a patient with metastatic dermatofibrosarcoma protuberans. J Clin Oncol 2002;20:3586-3591.

15. Ballo MT, Zagars GK, Pisters P, Pollack A. The role of radiation therapy in the management of dermatofibrosarcoma protuberans. Int J Radiat Oncol Biol Phys 1998; 40:823-827. 